\title{
Rancang Bangun Alat Sebagai Layanan Notifikasi Air conditioner Yang Rusak Pada Bagian Kompresor
}

\author{
I Gede Agus Darmawan ${ }^{1}$, Lie Jasa ${ }^{2}$,Pratolo Rahardjo ${ }^{3}$ \\ [Submission: 09-09-2020, Accepted: 13-12-2020]
}

\begin{abstract}
Indonesia is a tropical country, where Indonesia has two seasons, namely the rainy season and the dry season. During the dry season, the weather becomes hot, so technology is needed that can convert hot air to cool.

AC (Air Conditioner) is a technology used to cool air through air circulation. AC is divided into two parts, namely indoor and outdoor. Indoor and outdoor are connected via a copper pipe which is the freon gas line. Freon gas will be pumped through the outdoor using a compressor engine to suppress the flow of freon gas to flow to the indoor evaporator and the compressor will suck up the freon gas again to the condenser on the outdoor because the compressor is the most important part of the air conditioner, the compressor must be regularly maintained by knowing the amperage. performance on the compressor. So the purpose of this study is to monitor the performance of the compressor.

This monitoring is done by designing a tool called LANCAR (notification service for damaged air conditioners). The LANCAR tool has three parts, namely hardware as a tool for detecting compressor performance amperage, software as notification media and for monitoring compressor ampere and database as data storage on the compressor. The hardware used is NodeMCU esp 8266, Sct-013, Sw-420 and 1 channel relay module. These parts will be connected to the IoT (internet of things) system where this tool is able to provide notifications when the compressor is damaged and compressor data will be stored in the database so that it can be seen by the AC owner.
\end{abstract}

Keyword-AC, Indoor, Outdoor, Compressor, LANCAR.

Indonesia merupakan negara tropis, dimana indonesia memiliki dua musim yaitu musim hujan dan musim kemarau. Pada saat musim kemarau cuaca menjadi panas sehingga diperlukannya teknologi yang bisa mengubah udara panas menjadi sejuk.

AC (Air Conditioner) merupakan teknologi yang

\footnotetext{
${ }^{1}$ Mahasiswa,Program Studi Teknik Elektro Fakultas Teknik Universitas Udayana, Jalan Bhuana Raya no 103,Denpasar 80117. Indonesia (telp:081939682960;email:agoesstarchild@gmail.com)

${ }^{2,3}$ Dosen,Program Studi Teknik Elektro Fakultas Teknik Universitas Udayana, Jln. Jalan Kampus Bukit Jimbaran 80361 INDONESIA (telp: 0361-703315; fax: 0361-4321; e-mail: 2liejasa@unud.ac.id, ${ }^{3}$ pratolo@unud.ac.id)
}

I Gede Agus Darmawan : Rancang Bangun alat Sebagai... digunakan untuk menyejukkan udara melalui sirkulasi udara. AC terbagi menjadi dua bagian yaitu indoor dan outdoor. Indoor dan outdoor terhubung melalui pipa tembaga yang merupakan jalur gas freon. Gas freon akan dipompa melalui outdoor menggunakan mesin kompresor untuk menekan aliran gas freon agar mengalir ke bagian evaporator indoor dan kompresor akan menghisap gas freon lagi hingga ke bagian kondensor pada outdoor, karena kompresor merupakan bagian terpenting pada AC maka kompresor harus dirawat secara rutin dengan mengetahui ampere kinerja pada kompresor. Jadi tujuan dari penelitian ini adalah untuk monitoring kinerja pada kompresor.

Monitoring ini dilakukan dengan cara merancang alat yang bernama LANCAR (layanan notifikasi air conditioner yang rusak). Alat LANCAR memiliki tiga bagian yaitu hardware sebagai alat untuk mendeteksi ampere kinerja kompresor, software sebagai media notifikasi serta untuk monitoring ampere kompresor dan database sebagai penyimpan data pada kompresor. Hardware yang digunakan yaitu NodeMCU esp 8266, Sct013,Sw-420 dan modul relay 1 channel. Bagian-bagian ini akan terhubung dengan sistem IoT (internet of things) dimana alat ini mampu memberikan notifikasi ketika kompresor dalam keadaan rusak dan data kompresor akan disimpan di dalam database agar nantinya dapat dilihat oleh pemilik AC.

Kata kunci- AC, Indoor, Outdoor,Kompresor, LANCAR.

\section{PENDAHULUAN}

Dengan perkembangan dan kemajuan teknologi modern pada saat ini yang begitu pesat, membuat semua orang selalu mencari tahu, mempelajari serta membuat alatalat yang bisa digunakan dalam kehidupan sehari-hari dan bermanfaat bagi banyak orang, bahkan tidak sedikit orang yang mengembangkan alat yang sudah ada menjadi lebih canggih lagi. Salah satunya yaitu AC (air conditioner) yang merupakan alat berfungsi untuk menyejukkan udara, dimana AC banyak digunakan pada daerah-daerah yang memiliki musim kemarau. AC memiliki dua bagian yaitu indoor dan outdoor. Bagian outdoor biasanya dipasang diluar agar sirkulasi pada outdoor lebih lancar. Outdoor memiliki komponen penting yaitu kompresor, dimana kompresor ini digunakan untuk menjalankan gas freon dari outdoor menuju indoor dengan cara menekan dan menghisap gas freon melalui pipa yang sudah terhubung. Apabila kompresor melewati batas kinerja maka kompresor bisa p-ISSN:1693 - 2951; e-ISSN: 2503-2372

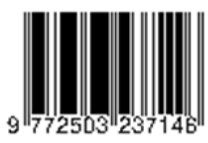


mengalami overheat atau overload dan menyebabkan kompresor cepat rusak sehingga menyebabkan AC tidak dingin. Permasalahan inilah yang memunculkan ide untuk mengintegrasikan AC dengan suatu alat yang dirancang yang diberinama LANCAR (layanan notifikasi AC yang rusak), dimana alat ini berfungsi untuk monitoring keadaan AC dan mengirimkan notifikasi kepada pemilik AC sehingga penanganan AC yang rusak menjadi lebih cepat.

Perancangan alat LANCAR ini dilengkapi dengan komponen NodeMCU ESP 8266 sebagai mikrokontroler, dan beberapa sensor pendukung seperti sensor arus dan sensor vibration. Seperti referensi penelitian [9] yang menggunakan sensor arus SCT-013, agar lebih mudah dalam penggunaannya untuk mendeteksi nilai arus, sehingga pada perancangan ini menggunakan sensor arus SCT-013

Mengingat teknologi semakin berkembang, sistem IoT sangat diperlukan di perusahaan atau ditempat-tempat yang memerlukan teknologi sebagai alat pendukung dalam bekerja. Seperti referensi penelitian [8] yang menggunakan sistem IoT untuk membantu monitoring suatu alat yang nantinya dapat mempermudah pekerjaan manusia sehingga pada perancangan alat yang bernama LANCAR menggunakan sistem IoT untuk dapat lebih cepat membantu penanganan AC melalui notifikasi, sehingga AC tidak cepat rusak tentunya juga dapat mengurangi biaya service pada AC.

\section{KAJIAN PUSTAKA}

\section{A. Air Conditioner}

Secara khusus pengertian dari air conditioner (AC) adalah suatu mesin yang digunakan untuk mendinginkan udara dengan cara menyirkulasikan gas refrigerant yang berada di pipa yang ditekan dan dihisap menggunakan kompresor.

Gas refrigerant dipilih sebagai bahan yang disirkulasikan dikarenakan bahan ini mudah menguap dan bentuknya bisa berubah-ubah, bisa berbentuk cairan maupun gas. Panas yang berada pada pipa kondensor berasal dari gas refrigerant yang ditekan oleh kompresor, sehingga bahan tersebut menjadi panas [3]. Cara kerja AC dapat dilihat pada gambar 1.

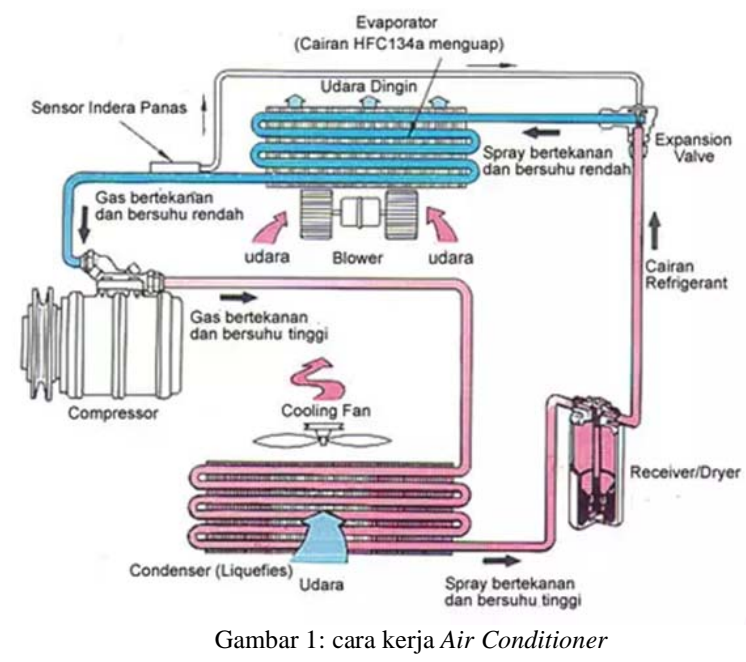

Prinsip pendingin udara pada AC melibatkan siklus refrigerasi, yaitu udara didinginkan oleh refrigerant atau pendingin (freon), kemudian gas freon ditekan menggunakan kompresor hingga mencapai tekanan tertentu dan menyebabkan suhunya naik, lalu didinginkan oleh udara lingkungan sehingga mencair. Proses tersebut berjalan berulang-ulang menjadi suatu siklus yang disebut siklus pendinginan pada udara yang berfungsi mengambil kalor dari udara dan membebaskan kalor ini keluar ruangan [5].

\section{B. $\quad$ Module NodeMCU ESP 8266}

NodeMCU ESP 8266 pada dasarnya adalah pengembangan dari ESP 8266 dengan firmware berbasis eLua. Pada NodeMCU ESP 8266 dilengkapi dengan micro USB port yang berfungsi untuk pemrograman maupun power supply. Selain itu, pada NodeMCU ESP 8266 dilengkapi dengan tombol yaitu reset dan flash.

NodeMCU ESP 8266 menggunakan bahasa pemrograman Lua yang merupakan package dari ESP 8266. Bahasa Lua memiliki logika dan susunan pemrograman yang sama dengan $\mathrm{C}$, namun hanya berbeda pada bagian syntax. Jika menggunakan bahasa Lua maka dapat menggunakan tool Lua loader maupun Lua uploder. Selain dengan bahasa Lua, NodeMCU ESP 8266 juga didukung dengan software Arduino IDE dengan melakukan sedikit perubahan board manager pada bagian Arduino IDE [11]. Sebelum Digunakan, Board ini harus di Flash terlebih dahulu agar mendukung tool yang akan digunakan. Apabila menggunakan Arduino IDE tentunya membutuhkan firmware yang cocok, yaitu firmware keluaran dari Ai-thinker yang mendukung At Command. Tool loader firmware yang digunakan adalah firmware NodeMCU.

\section{Sensor Arus Listrik AC SCT-013}

Teknologi sensor arus hampir sama dengan teknologi sensor tegangan yaitu dengan menggunakan trafo arus yang dikenal dengan Current Trafo (CT) dan menggunakan teknologi efek hall.

Sensor ini tergolong komponen yang memiliki tingkat stabilitas yang baik. Jenis sensor arus yang banyak dipakai adalah The Yhdc current transformer yang dikenal sebagai CT sensor yang merupakan sebuah non-invansive sensor yang dapat mendeteksi aliran arus melalui sebuah kawat penghantar. Dalam proses induksi, arus listrik yang melalui kawat sisi primer akan menghasilkan sebuah medan magnet pada inti ferrite CT sensor. Kawat pada sisi sekunder yang mengelilingi inti tersebut menghasilkan arus listrik kecil yang proporsional. CT sensor dengan penambahan sebuah resistor kecil (Burden Resistor) akan menghasilkan keluaran berupa tegangan yang dapat diolah oleh mikrokontroler melalui masukan analog to digital converter (ADC) [9].

\section{Sensor Vibration}

Sensor SW-420 adalah pendeteksi getaran yang beraksi terhadap getaran dari berbagai sudut.

Pada kondisi statis atau tanpa getaran, komponen elektronika berfungsi seperti saklar yang berada pada kondisi menutup (normally closed) dan bersifat konduktif, sebaliknya pada saat kondisi terguncang (terpapar getaran), 
saklar akan membuka atau menutup dengan kecepatan pengalihan (switching frequency) proporsional dengan kekerapan guncangan. Pengalihan bergantian secara cepat ini menyerupai cara kerja PWM (Pulse Width Modulation) yang merupakan sinyal pseudo-analog berupa tingkat tegangan yang kemudian dibandingkan oleh sirkuit terpadu LM 393 (Voltage Comparator IC) dengan besar nilai ambang batas (threshold) tegangan pembanding diatur oleh sebuah resistor eksternal [12].

\section{E. Modul Relay 1 Channel}

Relay adalah sebuah saklar yang dioperasikan secara listrik dan merupakan komponen Elektromechanical, yang terdiri dari dua bagian utama yaitu elektromagnet (Coil) dan mekanikal (kontak switch). Modul adalah susunan rangkaian elektronik yang difungsikan untuk kebutuhan pada rangkaian yang akan dihubungkan. Modul relay 1 channel digunakan untuk sebagai saklar dimana tegangan yang digunakan yaitu 5Vdc untuk dapat menjalankan kontak saklar pada relay[6].

\section{F. $\quad$ Android}

Android adalah salah satu sistem operasi (OS) yang berbasis linux untuk digunakan pada smartphone atau komputer dan tablet. Android adalah salah satu OS yang paling banyak digunakan pada smartphone. Hal ini dikarenakan android menyediakan platform yang terbuka atau open source bagi para pengembang untuk menciptakan berbagai aplikasi buatan mereka sendiri, yang digunakan sesuai keinginan dan tujuannya.

\section{G. Thunkable}

Thunkable adalah satu aplikasi atau tools IDE open source dimana thunkable tersedia untuk pembuatan aplikasi jenis mobile, yaitu android dan IOS dalam keperluan programmer atau mobile developer. Thunkable memberikan kemudahan dalam pembuatan aplikasi android maupun IOS, karena dalam perancangan interface digunakan sistem drag and drop elemen pallete. Sistem pemrogramannya menggunakan sistem pembuatan kode yang disebut dengan block yang menggunakan sistem drag and drop [7].

Thunkable juga sudah tersedia fitur google API (Application Programming Interface) yang sangat berguna dalam pengembangan aplikasi untuk memanfaatkan berbagai fitur yang disediakan oleh google, seperti Youtube, Google Map, Translation, Search Engine dan lainnya. API adalah kode program yang merupakan antarmuka atau penghubung antara aplikasi yang dibuat dengan fungsifungsi yang dikerjakannya. Google API memungkinkan program aplikasi yang dibuat dapat mengakses, menjalankan, dan memanfaatkan fungsi atau fitur yang disediakan oleh google [7].

H. Google Sheet

Google sheet merupakan aplikasi bagian dari google cloud, dimana dalam membuat dan berbagi sebuah spreadsheet, user hanya perlu memiliki akun gmail saja. Google sheet memiliki fitur dan fungsi yang hampir sama

I Gede Agus Darmawan : Rancang Bangun alat Sebagai... dengan Microsoft excel, tetapi yang membedakan antara google sheet dengan Microsoft excel adalah fitur share yang memungkinkan user untuk melakukan editing kaloborasi melalui internet. Google sheet dapat diprogram menggunakan bahasa pemrograman yang disediakan oleh google, yaitu google app script (gas). Bahasa pemrograman ini dapat dieksekusi melalui google cloud yang memungkinkan aplikasi-aplikasi yang terinteraksi dengan google cloud menggunakan GAS tersebut termasuk google sheer [1]. Internet of Things

Internet of thing yang dikenal dengan singkatan IoT, merupakan sebuah konsep yang bertujuan memperluas manfaat dari konektivitas internet yang tersambung secara terus-menerus. IoT digunakan untuk berbagi data, remote control, dan sebagainya, termasuk juga pada benda di dunia nyata. Contohnya bahan pangan, elektronik koleksi, peralatan apa saja, termasuk benda hidup yang semuanya tersambung ke jaringan lokal dan global melalui sensor yang tertanam dan selalu aktif [8].

\section{Metodologi Penelitian}

Penelitian ini merancang bangun alat yang digunakan sebagai layanan notifikasi pada air conditioner untuk monitoring kinerja pada AC. Adapun perancangan yang dilakukan dalam penelitian ini yaitu:

1. Tahapan study literature

2. Perancangan hardware

3. Perancangan software

Rancang bangun alat yang bernama LANCAR, dilakukan dengan mengumpulkan referensi, agar sesuai dengan perancangan alat yang diinginkan.

A. Tahapan study literature

Tahapan study literature merupakan tahapan awal untuk melakukan pengumpulan data-data yang berkaitan dengan penelitian yang dilaksanakan. Adapun data-data yang dikumpulkan berasal dari referensi, antara lain sebagai berikut:

1. Datasheet dari komponen elektronika dan alat yang digunakan pada penelitian

2. Jurnal-jurnal terkait yang sesuai dengan judul penelitian yang dilaksanakan

Setelah mendapatkan referensi yang cukup untuk merancang bangun alat ini, selanjutnya dilakukan perancangan hardware.

B. Perancangan hardware

Perancangan hardware dilakukan untuk mengetahui wiring dari komponen-komponen yang digunakan. Perancangan hardware terdiri dari:

1. Perancangan modul adaptor

2. Perancangan modul sensor arus SCT-013

3. Perancangan modul sensor vibration SW-420

4. Perancangan modul relay 1 channel

5. Perancangan keseluruhan

Setiap bagian perancangan akan disatukan dengan mikrokontroler NodeMCU ESP8266.

a. Perancangan modul adaptor

p-ISSN:1693 - 2951; e-ISSN: 2503-2372 
Pada perancangan ini, adaptor digunakan untuk menurunkan tegangan 220Vac dari power supply menjadi tegangan keluaran 5Vdc agar setiap komponen mendapatkan power sesuai dengan kebutuhan masing-masing komponen agar dapat bekerja dengan baik.

b. Perancangan modul sensor arus SCT-013

Modul sensor arus digunakan untuk mendeteksi arus dengan cara mengukur nilai arus pada kompresor. Sensor arus membutuhkan pin analog pada NodeMCU ESP8266 dan Sensor arus dapat bekerja dengan tegangan input sebesar 3 - 5Vdc, sehingga pin VCC pada sensor arus terhubung dengan pin 3vdc pada NodeMCU ESP8266. Sensor arus yang digunakan pada penelitian ini menggunakan tipe SCT-013 sistem non-invansive, yaitu menggunakan transformer CT sehingga memerlukan komponen pendukung untuk mendapatkan nilai arus yang sesuai.

c. Perancangan modul sensor vibration SW-420

Modul sensor vibration digunakan untuk mendeteksi getaran yang ada pada kompresor yang menandakan bahwa kompresor hidup atau mati. Sensor vibration membutuhkan tegangan 3Vdc dan input pin digital untuk memberikan logika high dan low. Ketika kompresor tidak bergetar maka sensor vibration berlogika low dan ketika kompresor bergetar maka sensor vibration berlogika high. Sensor vibration yang digunakan pada penelitian ini menggunakan tipe SW-420.

\section{d. Perancangan modul relay 1 channel}

Modul relay yang digunakan pada penelitian ini adalah modul relay 1 channel dengan kebutuhan sumber tegangan $5 V d c$ yang terhubung dengan pin adaptor. Pada NodeMCU ESP 8266 tidak terdapat pin tegangan 5Vdc sehingga modul relay mengambil tegangan dari adaptor agar tidak terjadi kelebihan beban pada NodeMCU ESP8266. Modul relay 1 channel digunakan untuk mengendalikan kompresor yang ditandai dengan pin IN1 pada modul relay. Jika arus pada kompresor melebihi batas range yang telah di-setting di NodeMCU ESP 8266 maka modul relay 1 channel akan mematikan kompresor dengan memutus tegangan yang masuk ke kompresor dan apabila arus pada kompresor berada pada range yang telah di-setting maka kompresor akan kembali hidup dengan menyambungkan tegangan ke kompresor. Modul relay yang digunakan pada penelitian kali ini modul relay 1 channel dengan tegangan kerja $5 \mathrm{~V}$, dan dapat memutus tegangan kerja dari 220Vac sampai 240Vac.

\section{e. Perancangan keseluruhan \\ Perancangan sistem secara keseluruhan merupakan penggabungan dari semua komponen-komponen yang ada yang telah dihubungkan menjadi satu rangkaian, gambar rangkaian keseluruhan dapat dilihat seperti gambar 2 .}

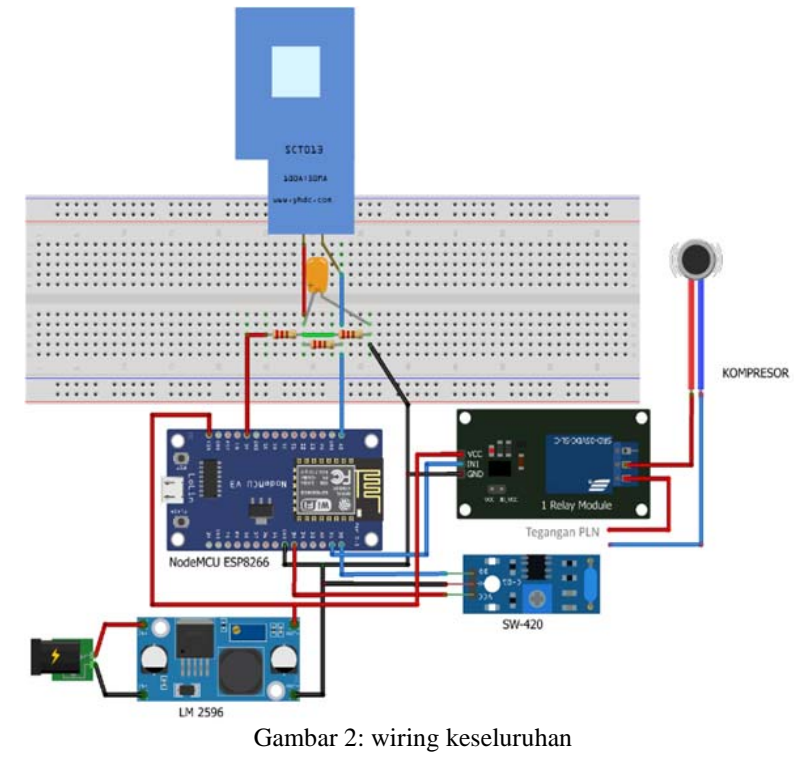

Perancangan keseluruhan dilakukan untuk mengetahui wiring dari keseluruhan komponen sehingga dapat bekerja dengan baik. Setelah perancangan hardware selesai, selanjutnya dilakukannya perancangan software untuk membuat suatu tampilan aplikasi yang dapat digunakan pada smartphone.

\section{Perancangan software}

Pada perancangan alat ini menggunakan beberapa software dalam pembuatan alat, yaitu software Arduino IDE 1.8.1, Thunkable, dan googlesheet. Setiap bagian perancangan software saling terhubung dengan satu sama lain.

a. Arduino IDE

Software Arduino IDE 1.8.1 digunakan untuk merancang program pada NodeMCU ESP8266. Program yang dirancang merupakan program untuk menjalankan NodeMCU ESP 8266 agar mampu menerima input dari semua modul sensor, dan mengendalikan modul relay. Selain itu, software Arduino IDE juga digunakan untuk merancang program pada NodeMCU ESP8266 agar dapat mentransmisikan data menuju database real-time yaitu googlesheet.

\section{b. Thunkable}

Software thunkable merupakan software yang digunakan untuk merancang mobile aplikasi android menggunakan metode program function block yang dapat diakses melalui https://thunkable.com. pada penelitian ini menggunakan software thunkable untuk merancang interface pada aplikasi android untuk mempermudah pengguna melakukan monitoring jarak jauh.

\section{c. Googlesheet}

Googlesheet merupakan platform database pengembangan dari google yang dapat diakses secara gratis menggunakan akun google. Database pada googlesheet dapat terintegrasi dengan mikrokontroler ESP8266 yang terhubung dengan jaringan internet. Pada penelitian ini, aplikasi android yang dirancang dapat menaruh data sensor yang di transfer oleh NodeMCU ESP8266 pada database. 


\section{HASIL DAN PEMBAHASAN}

A. Realisasi Hasil rancang bangun alat yang bernama LANCAR

Rancang bangun alat layanan notifikasi air conditioner yang rusak pada bagian kompresor terdiri dari 2 realisasi yaitu, realisasi hardware dan Realisasi software. Berikut merupakan hasil realisasi hardware dan realisasi software.

\section{Realisasi Hardware}

Hardware yang dirancang pada penelitian ini dibuat menggunakan komponen-komponen elektronika yang ada di-pasaran. Hardware ini dirancang agar dapat lebih cepat membantu penanganan pada kompresor AC yang mengalami gejala rusak. Alat ini bernama LANCAR (Layanan Notifikasi Air conditioner yang rusak). Realisasi hardware ditunjukkan pada Gambar 3 dan 4.

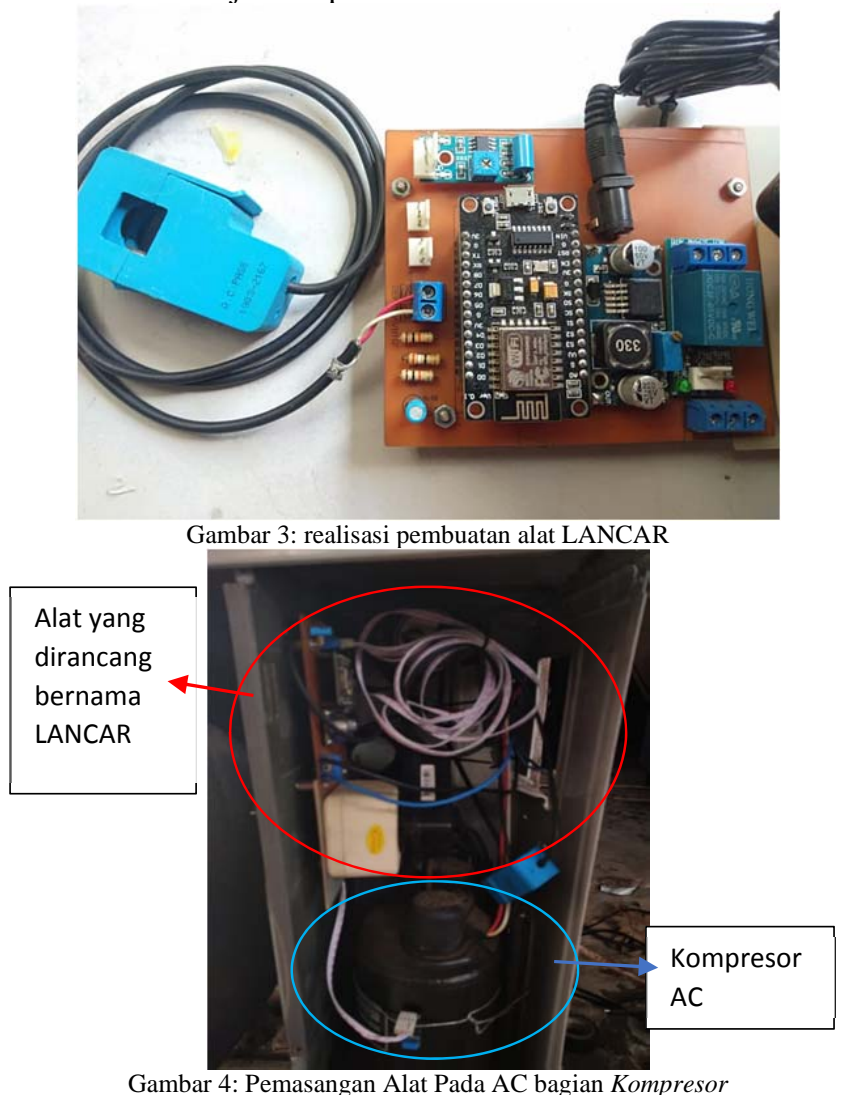

Alat LANCAR digunakan untuk mendeteksi dan monitoring kinerja kompresor. Dimana untuk mendeteksi kinerja kompresor menggunakan sensor arus dan getar. Alat ini menggunakan sensor SCT-013 sebagai sensor arus dan SW-420 sebagai sensor getar. Sensor arus digunakan untuk membaca berapa nilai arus yang ada pada kompresor dan sensor getar akan mendeteksi getaran yang ada pada kompresor namun getaran ini hanya sebagai indikator apakah kompresor hidup atau mati. Kompresor yang memiliki gejala rusak biasanya terdapat nilai arus yang tidak sesuai dengan standar operasi yang ada pada kompresor.

I Gede Agus Darmawan : Rancang Bangun alat Sebagai...
2. Realisasi Aplikasi Android

Aplikasi yang dirancang pada penelitian ini dibuat menggunakan software Thunkable berbasis pada Operating System Android. Aplikasi ini dirancang untuk dapat melakukan pemantauan jarak jauh pada alat LANCAR yang dipasangkan pada kompresor air conditioner. Aplikasi android terhubung dengan database googlesheet melalui jaringan internet. Realisasi aplikasi ditunjukkan pada gambar 5.

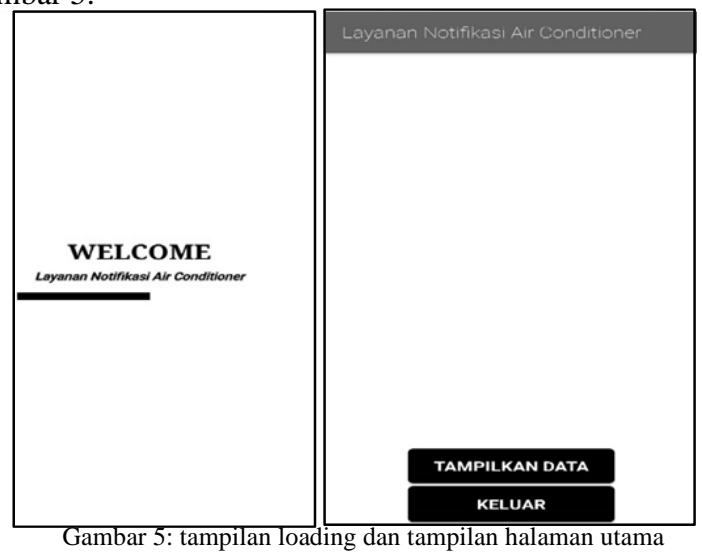

Aplikasi pada penelitian ini dirancang untuk dapat melakukan monitoring terhadap kompresor pada Air conditioner yang telah dipasangkan alat LANCAR dimana alat LANCAR membaca ampere pada kompresor dan akan mengirim notifikasi ke aplikasi bila terjadi kerusakan, yaitu dimana arus pada kompresor tidak sesuai dengan standar operasi yang dimiliki pada kompresor dan kompresor terjadi overheat (panas berlebihan).

B. Pengujian dan Pembahasan Hasil Perancangan Sistem Layanan Notifikasi AC yang rusak pada bagian kompresor

Rancangan Sistem Layanan Notifikasi AC yang rusak pada bagian kompresor terdiri dari beberapa blok rangkaian yang saling berkaitan. Pada masing-masing blok tersebut dilakukan pengujian satu persatu untuk dapat mempermudah melakukan troubleshooting sehingga tidak terjadi masalah saat melakukan pengujian sistem secara menyeluruh. Blok-blok tersebut diantaranya adalah:

1. Pengujian dan Pembahasan Modul LM2596

Pengujian dan pembahasan modul LM2596 bertujuan untuk mengetahui besar tegangan yang dihasilkan oleh modul LM2596 sesuai dengan kebutuhan tegangan yang diperlukan untuk mensuplai NodeMCU ESP8266 dan modul Relay 1 channel. LM2596 sendiri berfungsi untuk menurunkan tegangan input dengan mengubah variable resistor yang ada pada modul. Pengujian dilakukan dengan menggunakan multimeter digital, yaitu dengan cara menghubungkan probe positif pada pin output positif LM2596 dan probe negatif pada pin output negatif LM2596. Tegangan kerja yang dibutuhkan oleh NodeMCU ESP8266

p-ISSN:1693 - 2951; e-ISSN: 2503-2372 
sebesar 5V. Pada penelitian ini tegangan input yang diterima modul LM2596 sebesar 12V dari Adaptor dan diturunkan menjadi 5V. Diagram blok pengujian modul LM2596 dapat ditunjukkan pada Gambar 6.

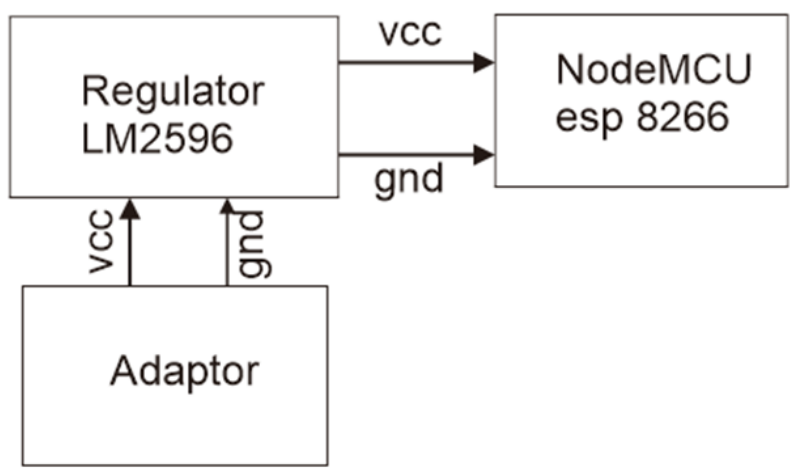

Gambar 6: diagram blok regulator LM 2596

Gambar 6 merupakan diagram blok power supply pada alat LANCAR, dimana dari adaptor akan menurunkan tegangan menjadi $12 \mathrm{Vdc}$ dan tegangan $12 \mathrm{Vdc}$ akan diturunkan lagi menjadi $5 \mathrm{Vdc}$ menggunakan regulator LM2596 dan nantinya tegangan ini akan mensupply komponen elektronik yang ada pada alat. Pengujian akan dilakukan untuk mengetahui apakah regulator LM2596 bisa menurunkan tegangan menjadi 5Vdc ditunjukkan pada tabel I.

TABEL I

HASIL PENGUJIAN TEGANGAN OUTPUT REGULATOR LM 2596

\begin{tabular}{|c|c|c|c|c|c|}
\hline $\begin{array}{l}\mathbf{N} \\
\mathbf{0} .\end{array}$ & $\begin{array}{c}\text { Pengukura } \\
\mathrm{n}\end{array}$ & $\begin{array}{c}\text { Paramet } \\
\text { er }\end{array}$ & $\begin{array}{c}\text { Hasil } \\
\text { Pengukura } \\
\mathbf{n}\end{array}$ & $\begin{array}{c}\text { Tampilan } \\
\text { Multimeter Digital }\end{array}$ & $\begin{array}{c}\text { Keteranga } \\
\text { n }\end{array}$ \\
\hline 1 & $\begin{array}{l}\text { Pengujian } \\
\text { Tegangan } \\
\text { Output } \\
\text { Regulator } \\
\text { LM2596 }\end{array}$ & $\begin{array}{l}\text { Besar } \\
\text { Tegangan } \\
\text { Output }\end{array}$ & $5.0 \mathrm{~V}$ & 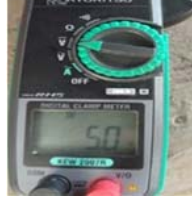 & Sesuai \\
\hline
\end{tabular}

Pengujian ini dilakukan untuk mengetahui apakah tegangan pada regulator stepdown sudah sesuai dengan tegangan yang dibutuhkan NodeMCU esp 8266. Pada pengujian ini menggunakan alat ukur avo meter dimana range pada avo di set menjadi Vdc dan probe merah dihubungkan pada kaki positif dan probe hitam dihubungkan dengan kaki negatif agar sesuai dengan tegangan yang dibutuhkan NodeMCU ESP 8266, sehingga dapat dikatakan bahwa regulator stepdown sudah berfungsi dengan baik.

2. Pengujian dan Pembahasan Sensor Arus SCT-013 Pengujian sensor arus SCT-013 bertujuan untuk mengetahui kinerja kompresor yaitu dengan membandingkan nilai arus yang ada pada label spesifikasi kompresor dengan pembacaan nilai arus pada sensor arus SCT-013. Modul sensor arus SCT-013 dapat bekerja pada tegangan input sebesar 3,3V yang terhubung pada NodeMCU ESP 8266.

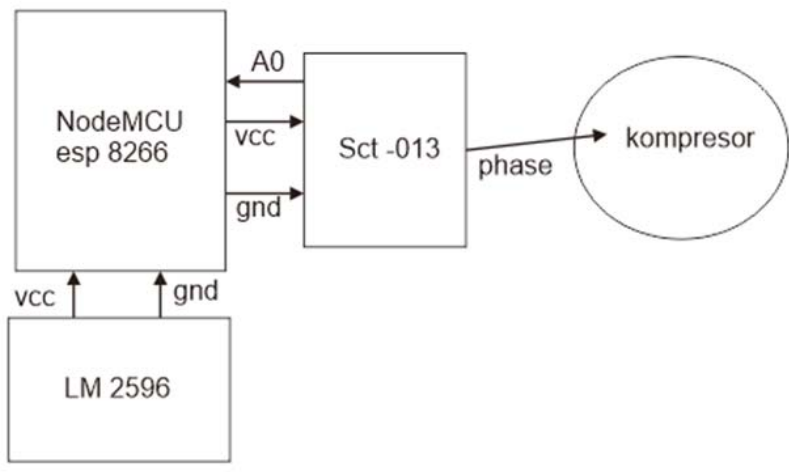

Gambar 7: Diagram Blok Pengujian Sensor Sct-013.

Pengujian modul sensor arus SCT-013 dilakukan dengan cara menjepitkan atau clamp modul sensor arus pada kabel tegangan AC yang ada di kompresor. Hasil pengukuran yang ditampilkan pada serial monitor akan dibandingkan dengan pengukuran menggunakan ampere meter. Berikut ini merupakan hasil pengujian modul sensor arus SCT-013 yang dapat ditunjukkan pada gambar 22.

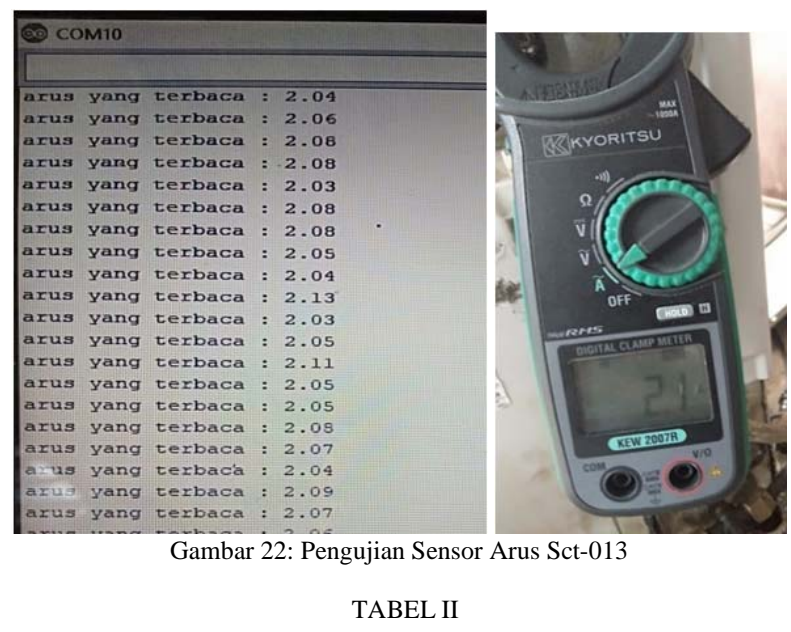

PERBANDINGAN HASIL PENGUKURAN AMPERE PADA ALAT DAN AMPERE METER

\begin{tabular}{|c|c|c|c|}
\hline hari & $\begin{array}{c}\text { Hasil } \\
\text { Pengukuran } \\
\text { dengan Sensor }\end{array}$ & $\begin{array}{c}\text { Hasil } \\
\text { Pengukuran } \\
\text { dengan } \\
\text { ampere meter }\end{array}$ & $\begin{array}{c}\text { Persentase } \\
\text { Kesalahan } \\
\text { Pengukuran } \\
\text { Sensor }\end{array}$ \\
\hline 1. & $2.11 \mathrm{~A}$ & $2.1 \mathrm{~A}$ & $0 \%$ \\
\hline 2. & $2.04 \mathrm{~A}$ & $2.1 \mathrm{~A}$ & $1 \%$ \\
\hline 3. & $2.13 \mathrm{~A}$ & $2.2 \mathrm{~A}$ & $4 \%$ \\
\hline
\end{tabular}

Pengujian ini dilakukan pada air conditioner dengan spesifikasi $1 / 2 \mathrm{pk}$. Pada tabel II terdapat perbandingan arus yang diukur melalui sensor arus dan ampere meter. Hasil yang didapatkan tidak terlalu jauh perbedaannya dan hampir mendekati hasil pengukuran menggunakan ampere meter, sehingga pada pengujian ini alat LANCAR dapat dikatakan bekerja dengan baik. 
3. Pengujian dan Pembahasan Modul sensor vibration SW-420

Pengujian modul sensor vibration SW-420 bertujuan untuk mengetahui apakah kompresor hidup atau mati yaitu dengan cara menempelkan sensor getar di kompresor sehingga getaran yang ada pada kompresor akan dibaca high ataupun low. Modul sensor vibration SW-420 dapat bekerja pada tegangan input sebesar 5Vdc.

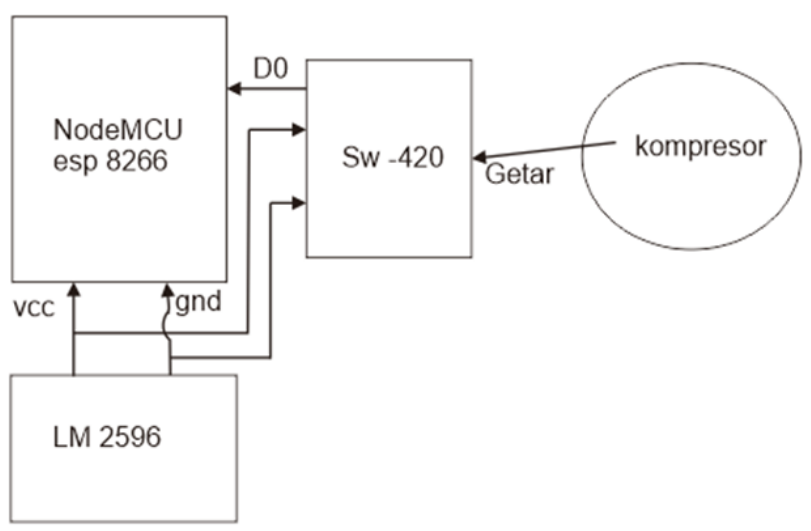

Gambar 8: Diagram Blok Pengujian Sensor Sw-420

Berdasarkan pada Gambar 8 dapat diperlihatkan bahwa modul SW-420 digunakan untuk membaca getaran pada kompresor. Pin data pada sensor getar terhubung dengan pin D0 NodeMCU esp 8266. Sensor getar akan mendeteksi getaran pada kompresor dan akan mengirimkan data logika Low dan High ke mikrokontroler dan nantinya akan mengirimkan kondisi kompresor ke database.

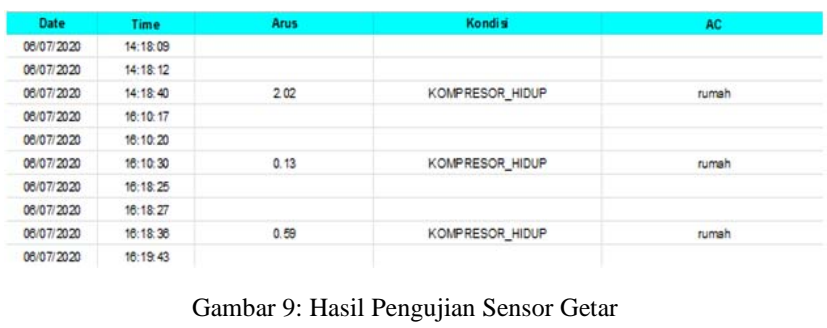

Gambar 9 menunjukkan hasil pengujian pada sensor getar. Sensor getar mendeteksi getaran yang ada pada kompresor. Getaran ini akan digunakan sebagai indikator apakah kompresor hidup atau mati. Nilai ampere pada gambar menunjukkan bahwa kompresor hidup, sehingga ketika ampere normal maka kondisi pada kompresor adalah dikatakan hidup. Pada pengujian kali ini dapat dikatakan bahwa sensor getar berfungsi dengan baik.

4. Pengujian dan Pembahasan Modul Relay 1 Channel Pengujian modul relay 1 channel ini bertujuan untuk mengetahui respon pada saat kompresor mengalami kerusakan dan pada saat kompresor tidak terjadi kerusakan. Modul relay 1 channel ini digunakan sebagai saklar pada kompresor. Modul relay ini dihubungkan kabel tegangan AC

I Gede Agus Darmawan : Rancang Bangun alat Sebagai... yang menuju ke kompresor, sehingga pada saat kompresor mengalami kerusakan maka relay akan $O N$. Pada saat kompresor tidak rusak atau (normal) maka relay akan OFF. Modul relay 1 channel ini dapat bekerja pada tegangan input sebesar $5 \mathrm{Vdc}$ dan modul relay ini dapat memutus tegangan 220 - 230 Vac dengan ampere maksimal 10A. Berikut blok diagram pada modul relay 1 channel.

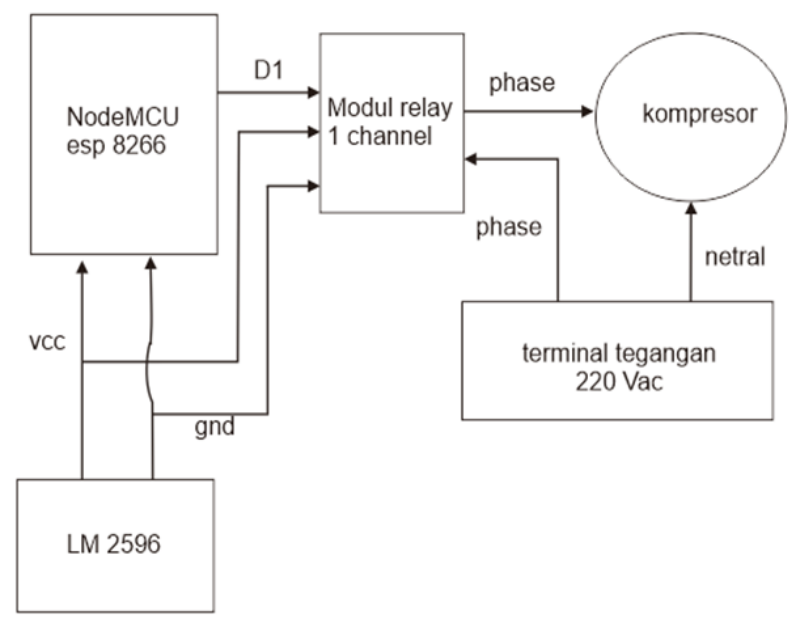

Gambar 10: Diagram blok modul relay 1 channel

Berdasarkan pada Gambar 10 dapat ditunjukkan bahwa NodeMCU esp 8266 dapat mengendalikan modul relay 1 channel melalui pin digital yang terhubung dengan pin input data pada modul relay. Pin digital yang digunakan pada penelitian ini adalah pin D1 yang terhubung dengan NodeMCU esp 8266. Pada diagram diatas relay terhubung dengan tegangan yang masuk ke kompresor, apabila kompresor rusak maka relay akan memutus tegangan yang dikendalikan melalui NodeMCU esp 8266. Relay di suplai dari regulator LM 2596 langsung karena memerlukan tegangan $5 \mathrm{~V}$.
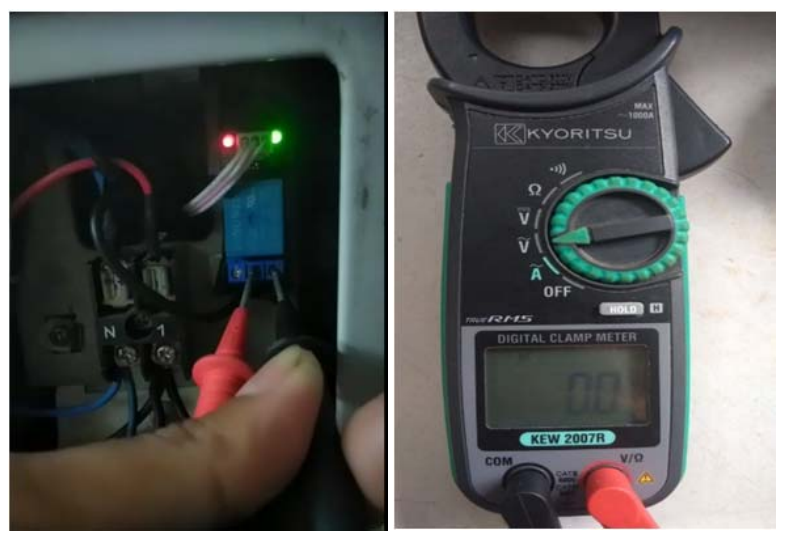

Gambar 11: Pengujian Pada Modul Relay Ketika Kompresor Rusak

Gambar 11 menunjukkan hasil pengujian pada modul relay 1 channel. Modul relay ini dikendalikan menggunakan NodeMCU esp 8266. Ketika ampere pada kompresor tidak

p-ISSN:1693 - 2951; e-ISSN: 2503-2372 
sesuai dengan standar operasinya maka relay akan memutus tegangan yang masuk pada kompresor sehingga kompresor menjadi tidak cepat rusak. Pada pengujian ini dapat dikatakan bahwa modul relay 1 channel pada bekerja dengan baik.

C. Pengujian alat pada AC $1 \frac{2}{2} \mathrm{Pk}$ selama 1 minggu

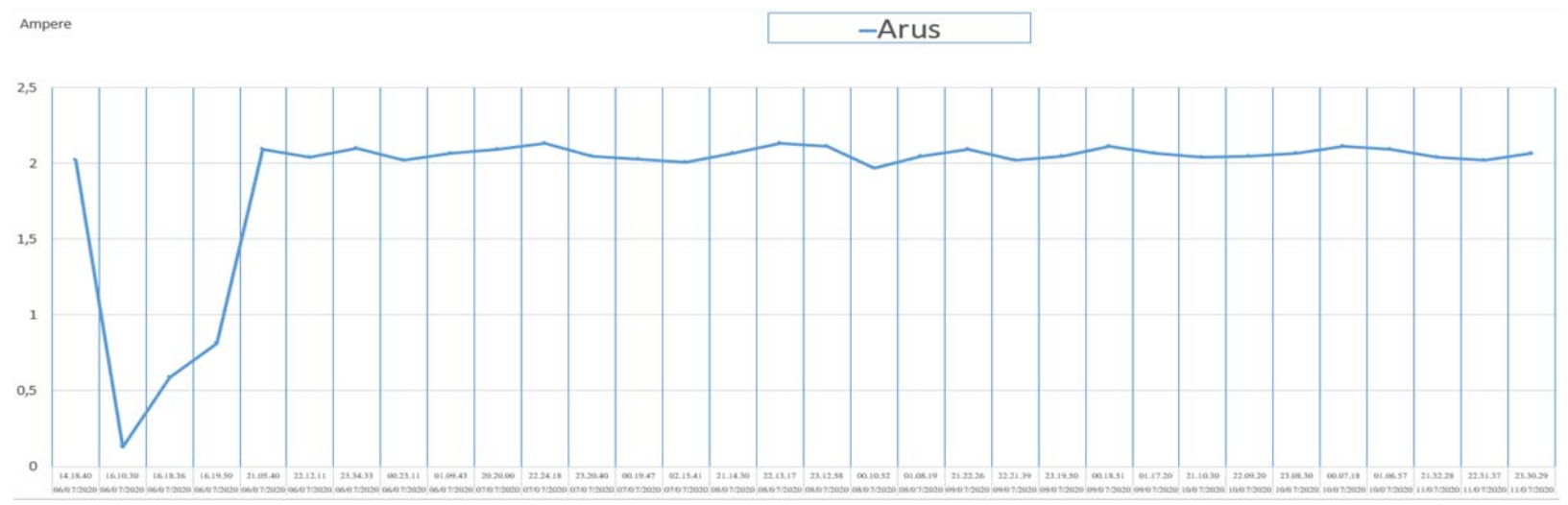

Gambar 12 : Pengujian Pada alat selama 1 minggu.

Gambar 12 merupakan Pengujian pada alat selama 1 minggu, pengujian ini dilakukan untuk mengetahui apakah alat ini dapat bekerja dan memonitoring AC selama 1 minggu. AC yang digunakan pada penelitian ini yaitu AC 1/2 pk merk Sharp. Pada pengujian ini menggunakan WiFi hostpot pribadi. Terlihat pada tanggal 6 juli 2020 terdapat penurunan ampere pada kompresor, dikarenakan pada tanggal tersebut AC mengalami kerusakan pada instalasi pipa freon, dimana terjadi kebocoran gas freon sehingga terjadi penurunan nilai arus pada grafik. Ampere kembali normal pada tanggal 7 juli 2020, setelah kebocoran gas freon diperbaiki dan diisi ulang sesuai dengan standar operasi AC. Pada tanggal 8 juli sampai tanggal 12 juli 2020 terlihat bahwa AC tidak mengalami penurunan arus sehingga AC dalam kondisi normal. Setelah didapatkan data tersebut dapat dikatakan bahwa alat ini dapat beroperasi.

\section{KESIMPULAN}

Simpulan dari penelitian ini adalah sebagai berikut:

Alat LANCAR menggunakan NodeMCU esp 8266 digunakan sebagai mikrokontroler. Alat LANCAR harus terhubung internet untuk dapat bekerja. Alat LANCAR bekerja pada tegangan 220-240Vac dan ampere maksimal dari regulator LM 2596 adalah 3 ampere.

Pengujian alat dilakukan dengan pengujian setiap blok pada alat agar sesuai dengan nilai referensi yang diberikan dan perbandingan nilai pada alat LANCAR dengan nilai pada alat ukur.

Perancangan ini juga merancang sebuah aplikasi yang berfungsi untuk menerima notifikasi bila terjadi kerusakan pada kompresor dan menampilkan data pada database sehingga lebih mudah dalam monitoring kompresor.

\section{REFERENSI}

[1] Andrew Childress, 2018. Bagaimana Cara Menggunakan Google Sheets untuk Membuat Spreadsheet Pertama Anda. [Online]. Tersedia pada: https://business.tutsplus.com/id/tutorials/how-to-use-googlesheets-to-make-spreadsheet--cms-30942.

[2] Arlina, 2015. Kelebihan dan Kelemahan Internet of Things. [Online] Tersedia Pada: http://renyshahputri.blogspot.com/2018/04/kelebihandan-kelemahan-internet-of.html

[3] Ariffandi Saputra.,2012 AIR CONDITIONER (AC). [Online] Tersedia Pada:http://air-conditioner-ariffandisaputra.blogspot.com/2012/03/babiii-pengetahuan-dasar-tentang-ac.html.

[4] Damayanti. 2017. Adaptor. [Online]. Tersedia pada: https://www.google.com/url?sa=t\&rct=j\&q=\&esrc=s\&source=web\&cd $=2 \&$ cad $=$ rja\&uact $=8 \&$ ved $=2$ ahUKEwjX2OqGmdTmAhXNWisKHf3h AasQFjABegQICxAE\&url=http\%3A\%2F\%2Feprints.polsri.ac.id\%2F4 537\%2F3\%2FFile\%2520III.pdf\&usg=AOvVaw3MkqTE6NkaxIs6Kzo I8_-r.

[5] Dewade. 2016. Prinsip kerja AC split. [Online]. Tersedia Pada: http://egsean.com/prinsip-kerja-ac-split/ .

[6] Dickson Kho. 2019. Pengertian Relay dan Fungsinya. [Online]. Tersedia pada: https://teknikelektronika.com/pengertian-relay-fungsirelay/.

[7] Made Yoga Mahaputra I.G.A, Putu Raka Agung I.G.A, Lie Jasa.,2019. Rancang Bangun Sistem Keamanan Sepeda Motor Dengan GPS Tracker Berbasis Mikrokontroler dan Aplikasi Android. Universitas Udayana. Tersedia pada:

[8] Putu Mastawan Eka Putra I.G, Ida Ayu Dwi Giriantari, Lie Jasa., 2017. Monitoring Menggunaan Daya Listrik Sebagai Implementasi Internet of Things Berbasis Wireless Sensor Network. Universitas Udayana Tersedia pada: https://doi.org/10.24843/MITE.2018.v17i01.P03.

[9] I Wayan Rexci Indra Parmana, Cok Gede Indra Partha, Ngakan Putu Satriya Utama,. 2018. Rancang Bangun Sistem Monitoring Arus Beban pada Gardu Distribusi Menggunakan Short Message Service. Universitas Udayana. Tersedia pada :

[10] Vina Rahmawati, Aan Tohir Efendi. 2017. Sistem Pengendali Pintu Berbasis Web Menggunakan Nodemcu 8266. Universitas STMIK AKAKOM Yogyakarta. Tersedia pada:

[11] Rahmawati. 2017. nodemcu. [Online]. Tersedia pada: https://www.google.com/url?sa=t\&rct=j\&q=\&esrc=s\&source=web\&cd =2\&ved=2ahUKEwigp5f_kdTmAhUDOisKHcLaAaUQFjABegQIBx AC\&url=http\%3A\%2F\%2Feprints.akakom.ac.id\%2F4914\%2F3\%2F3_ 143310009_BAB_ll.pdf\&usg=AOvVaw0CgetGlikI9184DStpSKMc.

[12] Siahaan. 2017. Sensor SW420. [Online]. Tersedia Pada: https://www.google.com/url?sa=t\&rct=j\&q=\&esrc=s\&source=web\&cd =1\&ved=2ahUKEwj_5rwm9TmAhWKbysKHVzDBE8QFjAAegQIB BAC\&url=http\%3A\%2F\%2Frepository.dinamika.ac.id\%2Fid\%2Feprin t\%2F2284\%2F5\%2FBAB_III.pdf\&usg=AOvVaw3SXqBbfMkyY4zdA UH5z3N8. 